\title{
Anvillea garcinii extract inhibits the oxidative burst of primary human neutrophils
}

Hanane Boukemara ${ }^{1,2,3,5}$, Margarita Hurtado-Nedelec ${ }^{1,2,3,4}$, Viviana Marzaioli, 2,3, Dalila Bendjeddou', Jamel El Benna $a^{1,2,3}$ and Jean-Claude Marie ${ }^{1,2,3^{*}}$

\begin{abstract}
Background: Anvillea garcinii Coss. \& Durieu (Anv) plant is used as a traditional North African medicine against several diseases associated with inflammation. At inflammatory sites, reactive oxygen species (ROS) produced in excess by activated phagocyte NADPH oxidase (NOX2) can accentuate inflammatory responses. Thus, we investigated if Anv-water soluble polysaccharides could modulate primary human neutrophil oxidative burst in vitro.

Methods: Human neutrophils were isolated from fresh whole blood and $\mathrm{O}_{2}{ }^{-}$generation was measured by cytochrome $\mathrm{c}$ reduction assays. Western blots were used to analyse the translocation of PKC, p47 ${ }^{\text {phox }}$ (a key component of NOX2 activity) to neutrophil plasma membrane. Also, myeloperoxidase (MPO) release in the extracellular medium was studied by western blots. Flow cytometric analysis was used to detect CD11b membrane expression.

Results: Water soluble polysaccharides from Anv dose-dependently inhibited N-formyl-methionyl-leucylphenylalanine (fMLF)- and phorbol myristate acetate (PMA)-induced $\mathrm{O}_{2}{ }^{-}$generation by human neutrophils. Moreover, Anv-polysaccharides strongly inhibited PMA-induced PKC $\beta$ and p47 $7^{\text {phox }}$ translocation to membranes and p47 $7^{\text {phox }}$ phosphorylation on Ser328, a main PKC target. In contrast, polysaccharides extract from Zygophyllum gaetulum plant, which is also used as a traditional North African medicine against inflammatory diseases, was ineffective on this PKC $\beta$-p47phox pathway. Further, Anv inhibited important neutrophil degranulation markers corresponding to myeloperoxidase (MPO) release and CD11b membrane expression.
\end{abstract}

Conclusion: The process of down-regulating NADPH oxidase by polysaccharides extracts from Anv provides new insights into the mechanism of Anv's anti-inflammatory actions.

Keywords: Inflammation, NADPH oxidase, Anvillea garcinii, Zygophyllum gaetulum, North Africa

\section{Background}

Increased reactive oxygen species (ROS) can damage healthy bystander tissues, thereby contributing to several inflammatory diseases such as rheumatoid arthritis and inflammatory bowel diseases [1]. Neutrophil is the main ROS producing phagocyte which play an essential role in host defence against microbial pathogens and in inflammation. In response to stimulating agents such as

\footnotetext{
* Correspondence: jean-claude.marie@inserm.fr

'INSERM, U1149, CNRS-ERL8252, Centre de Recherche sur I'Inflammation (CRI), 16 rue Henri Huchard, 75018 Paris, France

¿Université Paris Diderot, Sorbonne, 75018 Paris, France

Full list of author information is available at the end of the article
}

the bacterial peptide $N$-formyl-methionyl-leucylphenylalanine (fMLF), neutrophils release large amounts of superoxide anion $\left(\mathrm{O}_{2}^{-{ }^{-}}\right)$and other reactive oxygen species (ROS) such as hydrogen peroxide $\left(\mathrm{H}_{2} \mathrm{O}_{2}\right)$, used by myeloperoxidase (MPO) to produce hypochloric acid, in a phenomenon called the respiratory burst [2]. Nicotinamide adenine dinucleotide phosphate (NADPH) oxidase or NOX2, the enzyme responsible for superoxide anion production by phagocytes, is a multicomponent enzyme system consisting of membrane associated cytochrome b558 (composed of gp91 ${ }^{\text {phox }}$ and $\mathrm{p} 22^{\text {phox }}$ ) and the cytosolic components $\mathrm{p} 47^{\text {phox }}, \mathrm{p} 67^{\text {phox }}, \mathrm{p} 40^{\text {phox }}$, and $\operatorname{rac} 1 / 2$ (a small GTPase) [3, 4]. Neutrophil activation leads to 
phosphorylation of the cytosolic components such as $\mathrm{p} 47^{\text {phox }}$, a protein which plays an important role in the assembly and activation of NADPH oxidase.

Activated neutrophils and several associated products such as ROS, myeloperoxidase (MPO), elastase and inflammatory adipokines have been found in synovial fluid of patients with rheumatoid polyarthritis $[5,6]$. Neutrophils are highly mobile cells which are densely packed with secretory granules. Degranulation, a mechanism independent of ROS production, can also be incriminated as being a main cause of pulmonary disorders such as severe asphyxic episodes of asthma [7]. The dual role of neutrophils has been further highlighted during respiratory viral infection whereby it contributed to beneficial antiviral responses as well as detrimental tissue pathology and cellular inflammation [8]. Thus, the inhibition of excessive oxidant production and degranulation represent an important therapeutic target and could in part explain the beneficial effects of certain natural products used against inflammatory disorders. To this end, bioactive products isolated from medicinal plant such as Garcinia buchananii and Ficus aurantiaca Griff have been shown to be antioxidative by respectively displaying in vitro $\mathrm{H}_{2} \mathrm{O}_{2}$ scavenging activity [9] or inhibiting neutrophil ROS production [10]. Indeed, integration of the wealthy African medication for several diseases including inflammation in western medicine is considered as a promising challenge [11]. Medicinal plant extracts are usually made with water and water-soluble polysaccharides isolated from plants have attracted much attention because of their broad spectrum of therapeutic properties and relative low toxicity [12].

In this context, we investigated if water-soluble polysaccharide-extract from an endemic plant which grows in northern Africa and particularly in Morocco and Algeria, Anv, could have anti-inflammatory effects. This plant is known by traditional healers to possess several medicinal properties in North-African countries [13]. For example, their crude extracts as well as their infusions are widely used to treat colds, diabetes, stomach and liver diseases often associated with inflammation and they are also antiseptic and antispasmodic [14-16].

Our study shows that Anvillea garcinii Coss. \& Durieu water-soluble polysaccharide extract was efficient in inhibiting ROS production and degranulation of primary human phagocytes. Indeed, $A n v$ was efficient in inhibiting neutrophil superoxide anion induced by PMA or fMLF. Analysis of the mechanism indicated a selective inhibition of a strong PKC phosphorylation site, Ser 328 on $\mathrm{p} 47^{\text {phox }}$ crucial for the assembly and function of neutrophil NOX2.

\section{Methods}

\section{Reagents}

Phorbol myristate acetate (PMA), formyl-methionylleucylphenylalanine (fMLF), Tween 20, luminol, cytochrome $c$, horse radish peroxidase (HRP), phosphatases inhibitors and proteases inhibitors, ATP, HBSS, acetylsalicylic acid and PBS and other chemicals were purchased from Sigma Aldrich (Saint-Quentin Fallavier, France). Dextran T500 and Ficoll were purchased from GE Healthcare (Orsay, France). HEPES was from life technologies (Saint Aubin, France). SDS-PAGE (sodium dodecyl sulphate-polyacrylamide gel electrophoresis), and Western blot were purchased from Bio-Rad (Richmond, CA, USA). Antibodies against protein kinase $C$ were from GeneTex (Irvine, CA, USA). Antibodies against, p22, Bactin as well as secondary HRP-labeled goat antirabbit antibodies were from Santa Cruz Biotechnology (Heidelberg, Germany). The anti-p47 $7^{\text {phox }}$ antibody was kindly provided by Dr. B. M. Babior (The Scripps Research Institute, La Jolla, CA, USA). The use of our rabbit polyclonal antibodies against phospho-sites p $47^{\text {phox }}$ (phospho-Ser328) have been described previously [17].

\section{Anvillea garcinii collection and preparation of water-soluble polysaccharide extract}

Anvillea garcinii Coss. \& Durieu (Anv) was collected from Biskra Ghardaya (north of Algerian Sahara) and was taxonomically authenticated by Dr. Ali Zitouni (University 8 Mai 1945 of Guelma, Algeria) and deposited at the herbarium of the university with the voucher specimen; (No.A.g.2010-1). A standardized water-soluble polysaccharide extract was prepared as described previously [18]. Briefly, $170 \mathrm{~g}$ of Anv powder, corresponding to the plant aerial part, was suspended in distilled water $(1 \mathrm{~g} / 20 \mathrm{~mL})$ and stirred for $3 \mathrm{~h}$ at $100{ }^{\circ} \mathrm{C}$ before cooling overnight at $8{ }^{\circ} \mathrm{C}$. The supernatant obtained by centrifugation for $30 \mathrm{~min}$ at $4000 \mathrm{~g}$ was reduced to half volume by evaporation. Polysaccharides were precipitated from the filtrates by the adding four volumes of ethanol (95\%). The precipitates $(16.48 \mathrm{~g}=9.7 \%)$ were collected by centrifugation for $30 \mathrm{~min}$ at $15,000 \mathrm{~g}$ and washed with ethanol and dried. The sample was dissolved in distilled water $(1 \mathrm{~g} / 50 \mathrm{~mL})$, dialysed against distilled water for $72 \mathrm{~h}$ at $4{ }^{\circ} \mathrm{C}$. The dialysis residue was treated with tri-chloro-acetic acid and sodium acetate to remove proteins. The crude polysaccharide mixtures were precipitated by ethanol and air dried. The percentage yield relative to dry samples weight was $3.18 \%$ and the presence of proteins was not detected by colorimetric methods $[19,20]$. Similarly, we also extracted watersoluble polysaccharides ( $2.48 \%$ yield) from another identified traditional medicinal plant from the same region, Zygophyllum gaetulum Emb. \& Maire (Zyg), [21]. It 
was collected and identified by by Dr. Ali Zitouni and deposited at the above herbarium with the voucher (No.A.g.2010-2).

\section{Neutrophil isolation from peripheral human blood}

Freshly drawn blood from healthy subjects was used to isolate neutrophils by dextran sedimentation and Ficoll fractionation [22]. After centrifugation at $400 \mathrm{~g}$ for $30 \mathrm{~min}$, neutrophil and monocyte/lymphocyte rings were collected. Erythrocytes were removed from neutrophils by hypotonic lysis. Following isolation, neutrophils were suspended in appropriate medium, such as Hank's balanced salt solution (HBSS). Cell purity and counting were determined by flow cytometry analysis (FACS Canto II cytometer (BD, San Jose, CA, USA) and Turks' blue staining respectively. The viability of neutrophils with or without the polysaccharides was also determined by differential permeability of DNA-binding dyes using the ViaCount reagent by ${ }^{\text {Guava }}$ easy Cyte (IFAS-Cytometry Bioscience, Millipore, St Quentin en Yvelines, France).

\section{Measurement of superoxide production}

To measure superoxide anion or $\mathrm{O}_{2}{ }^{-}$production, isolated neutrophils cells $\left(5 \times 10^{5}\right)$ were suspended in $500 \mu \mathrm{L}$ of HBSS containing $1 \mathrm{mg} / \mathrm{mL}$ cytochrome $c$ in the presence or absence of different concentrations of Anv. The samples were placed in the thermostated chamber of a spectrophotometer (Uvikon, Thermo Fisher, Villebon, France) preheated at $37{ }^{\circ} \mathrm{C}$. After 15 min, cells were stimulated with $10^{-6} \mathrm{M}$ of $\mathrm{N}$-formylmethionyl-leucyl-phenylalanine (fMLF) or $100 \mathrm{ng} / \mathrm{mL}$ of phorbol myristate acetate (PMA). Changes in absorbance were measured at $550 \mathrm{~nm}$ for $10 \mathrm{~min}$.

\section{Evaluating Anv scavenging activity of $\mathrm{O}_{2}{ }^{-}$}

To evaluate $\mathrm{O}_{2}{ }^{-{ }^{-}}$scavenging activity, the $\mathrm{O}_{2}{ }^{--}$generation substrate xanthine $(200 \mu \mathrm{M})$ and cytochrome $c$ $(1 \mathrm{mg} / \mathrm{mL})$ were incubated with different concentrations of polysaccharides of $A n v$ at $30{ }^{\circ} \mathrm{C}$ during $15 \mathrm{~min}$. The enzyme xanthine oxidase was added and the amount $\mathrm{O}_{2}{ }^{-}$ was measured by assaying the cytochrome $c$ reduction at $550 \mathrm{~nm}$ in a spectrophotometer (Uvikon) for $10 \mathrm{~min}$.

\section{Effect of Anv on neutrophil degranulation}

Neutrophils $\left(5 \times 10^{6}\right.$ per $500 \mu \mathrm{L}$ HBSS $)$ were incubated in the presence or the absence of different concentrations of $A n v$ for $15 \mathrm{~min}$ at $37{ }^{\circ} \mathrm{C}$. Then, they were stimulated with either $10^{-6} \mathrm{M}$ fMLF for $5 \mathrm{~min}$ or $100 \mathrm{ng} / \mathrm{mL}$ PMA for $15 \mathrm{~min}$. Degranulation was stopped by cooling cell aliquots in ice-cold methanol $\left(-80{ }^{\circ} \mathrm{C}\right)$ for $5 \mathrm{~s}$. Cells were then centrifuged $\left(4^{\circ} \mathrm{C}\right)$ for $8 \mathrm{~min}$ at $400 \mathrm{~g}$. Supernatants were removed and denatured with Laemmli sample buffer [23] for western blot analysis.
Flow cytometric analysis of the CD11b expression at neutrophil surface

Isolated neutrophils $\left(2.5 \times 10^{6}\right.$ per $500 \mu \mathrm{L}$ PBS $)$ were incubated at $37{ }^{\circ} \mathrm{C}$ for $15 \mathrm{~min}$ in the presence or the absence of $A n v$ extracts. Samples were then stimulated with fMLF $\left(10^{-6} \mathrm{M}\right)$ for $5 \mathrm{~min}$. The reaction was stopped by cooling the cell aliquots on ice. $100 \mu \mathrm{L}$ of each sample was then stained with $20 \mu \mathrm{L}$ of PE-conjugated antihuman CD11b monoclonal antibody (BD Biosciences, San Jose, CA) for $15 \mathrm{~min}$ at room temperature in the dark. Then the cells were washed twice with PBS at room temperature and analyzed by flow cytometry using FACS Canto II cytometer (BD Biosciences, San Jose, CA, USA) as described [6].

\section{PKC $\beta$ and $p 47^{\text {phox }}$ translocation to neutrophils plasma membrane}

The experiment was performed as described before [17], briefly neutrophils $\left(50 \times 10^{6}\right.$ per $\left.\mathrm{mL}\right)$ in HBSS buffer were incubated for $15 \mathrm{~min}$ at $37{ }^{\circ} \mathrm{C}$ in the absence (control) or the presence of either Anv or Zyg extract at $300 \mathrm{ug} / \mathrm{mL}$ and then cells were stimulated with $100 \mathrm{ng} / \mathrm{mL}$ PMA for $8 \mathrm{~min}$. The reaction was stopped by adding 4 volumes of ice-cold PBS and cells were pelleted by centrifugation at $400 \mathrm{~g}$ for $8 \mathrm{~min}$ at $4{ }^{\circ} \mathrm{C}$. The suspended cells were disrupted by sonication and centrifuged at $400 \mathrm{~g}$ for $8 \mathrm{~min}$. The postnuclear supernatant was loaded onto a discontinuous sucrose gradient (35\% sucrose, $15 \%$ sucrose), centrifuged for $45 \mathrm{~min}$ at $150,000 \mathrm{~g}$. The membrane fraction in the $15 \%$ sucrose layer was collected and washed in PBS before denaturing in Laemmli sample buffer. The samples were boiled for $3 \mathrm{~min}$ and stored at $-80{ }^{\circ} \mathrm{C}$ until use.

\section{Western blot analysis}

The different samples were subjected to $10 \%$ SDSPAGE using standard techniques [23]. The separated proteins were transferred to nitrocellulose, which was blocked with $5 \%$ non-fat dry milk in Tris-buffered saline with $0.1 \%$ tween-20 (TBST) for $1 \mathrm{~h}$. After blocking, the nitrocellulose membranes were incubated for $1 \mathrm{~h}$ at $37{ }^{\circ} \mathrm{C}$ or overnight at $-4{ }^{\circ} \mathrm{C}$ with specific antibodies (Anti MPO (1:5000), anti-phosphoSer328-p47 ${ }^{\text {phox }}$ (1:2000), anti$\mathrm{p} 47^{\text {phox }}(1: 5000)$, anti-PKC $\beta$ or $\left.\alpha(1: 1000)\right)$ followed by three washes with TBST, the membranes were incubated with HRP-labelled goat anti-rabbit or anti-mousse antibody (1:5000). After three washes with TBST, revelation was performed by a chemiluminescence method (luminol reagent, Santa Cruz Biotechnology, Santa Cruz, CA), according to the manufacturer instructions and using Amersham Imager 600 (LifeSciences, Velizy, France). The intensity of bands was quantified by densitometry using the Image J analysis program (National Institute of Health, 
USA). Alternatively, the membranes were incubated with an alkaline phosphatase-conjugated goat anti-mouse or goat anti-rabbit and proteins were revealed with the NBT/ BCIP reagents (Saint Louis, Missouri, USA) in the carbonate buffer (0.1 mM NaHCO $3,1 \mathrm{mM} \mathrm{MgCl} 2, \mathrm{pH} 9.8)$.

\section{Statistical analysis}

All results are expressed as mean \pm SEM. One-way analysis of variance with the Tukey-Kramer post hoc test for multiple comparisons was implemented using GraphPad Prism version 6.0 for Windows (GraphPad Software, San Diego, CA).

\section{Results}

\section{Anv inhibited superoxide production by neutrophil in response to PMA}

The effect of $A n v$ on ROS production by human neutrophils was compared with that of $Z y g$, another North African medicinal plant $Z y g$, which is similarly used to treat against inflammatory diseases, even though they are of different genus. We also studied the established anti-inflammatory drug, aspirin [10] and fMLF or PMA was used to stimulate ROS production which was measured by using luminol-amplified chemiluminescence as shown in Additional file 1. Anv was a strong inhibitor of ROS production with a similar $\mathrm{IC}_{50}$ value $(60 \mu \mathrm{g} / \mathrm{mL})$ for either fMLF or PMA response while $Z y g$ was poorly effective. The aspirin $\mathrm{IC}_{50}$ values were $200 \mu \mathrm{g} / \mathrm{mL}$ and $300 \mu \mathrm{g} / \mathrm{mL}$ for inhibiting fMLF or PMA response respectively. To gain further insight in the mechanism of $A n v$ inhibition, we explore its effect on the production of superoxide anion, the first product of NADPH oxidase. We used the cytochrome $c$ reduction assay which is a specific technique for measuring superoxide anion. As shown in (Fig. 1a) Anv dose-dependently inhibited $\mathrm{O}_{2}{ }^{-}$- production by human neutrophils stimulated with fMLF. Further, a dramatic inhibition of $\mathrm{O}_{2}{ }^{--}$production was observed in response to PMA. We investigated if this inhibition was due to a scavenging of $\mathrm{O}_{2}{ }^{--}$by $A n v$ extract by using the in vitro xanthine oxidase production of $\mathrm{O}_{2}{ }^{--}$. Results in (Fig. 1b), show that the production of $\mathrm{O}_{2}{ }^{--}$was not significantly altered in the presence of increasing concentrations of Anv. Taken together, the results are in favour of an $A n v$ effect on NADPH oxidase activity as opposed to a scavenging activity.

\section{Anv inhibited $\mathrm{p} 47^{\text {phox }}$ and PKC translocation to the neutrophil plasma membrane in response to PMA}

We investigated if Anv can modulate PMA-induced translocation of $\mathrm{p} 47^{\text {phox }}$ and PKC in neutrophils which represents a potential immuno-modulatory pathway. We compared the effect of $A n v$ with the water-soluble polysaccharide extract of $Z y g$ which did not modulate $\mathrm{O}_{2}{ }^{-}$production by human neutrophils in response to
PMA, thus suggesting the involvement of different mechanisms and represented a potential control versus active $A n v$ (data not shown). The results in (Fig. 2a, left panel) show that neither $A n v$ nor $Z y g$ was able to promote the translocation of $\mathrm{p} 47^{\text {phox }}$ to neutrophil plasma membrane in the resting state. When neutrophils were incubated with PMA, it stimulated a strong translocation of $\mathrm{p} 47^{\mathrm{phox}}$. This PMA-induced translocation was significantly inhibited in the presence of $A n v$ and not $Z y g$ as indicated by the histogram. Similar results were obtained with PKC $\beta$ showing that $A n v$ was effective in inhibiting $\mathrm{PKC} \beta$ translocation to plasma membrane in response to PMA (Fig. 2b). Further, activation of NADPH oxidase in neutrophils by PMA is known to be accompanied by a strong phosphorylation of Ser328 in the regulatory subunit, $\mathrm{p} 47^{\text {phox }}[24]$. We detected little or no phosphorylation using a specific antiphosphoSer328 antibody, in control samples (Fig. 2c), while PMA induced a strong Ser328 phosphorylation. Interestingly, $A n v$ at the same concentration used above $(300 \mu \mathrm{g} / \mathrm{ml})$ significantly inhibited this phosphorylation of $47^{\text {phox }}$ on Ser328 stimulated by PMA while $Z y g$ was ineffective.

\section{Anv inhibited neutrophil degranulation}

We investigated whether Anv extract could affect other important neutrophil functions such as degranulation. To this end, neutrophils were incubated without (control) and with 76 to $300 \mu \mathrm{g} / \mathrm{mL}$ of $A n v$ extracts and then stimulated with fMLF or PMA as described in methods. Then myeloperoxidase (MPO), the most abundant pro-inflammatory enzyme stored in azurophilic granules of neutrophils, was detected in the extracellular medium by using western blot analysis. The results (Fig. $3 \mathrm{a}$ and $\mathrm{b}$ ) show that $A n v$ was effective in inhibiting MPO release in the extracellular medium induced by either fMLF or PMA. Further, we analysed the effect of Anv on fMLF-induced degranulation of specific granules by measuring the neutrophil surface expression of CD11b. In (Fig. 3c), the data of flow cytometric analysis are presented as a percentage of control values (fMLF only) and showed that $A n v$ inhibited CD11b expression at the neutrophil outer membrane. Taken together, the results suggest that $A n v$ inhibits neutrophil degranulation processes.

\section{Discussion}

Innate immunity serves as an essential first-line of defense against microbial pathogens and foreign substances. Phagocytic cells such as neutrophils play a key role in innate immunity because of their ability to recognize, ingest and destroy pathogens by oxidative and nonoxidative mechanisms. However, neutrophil hyperactivation has been shown to induce tissue injury and 


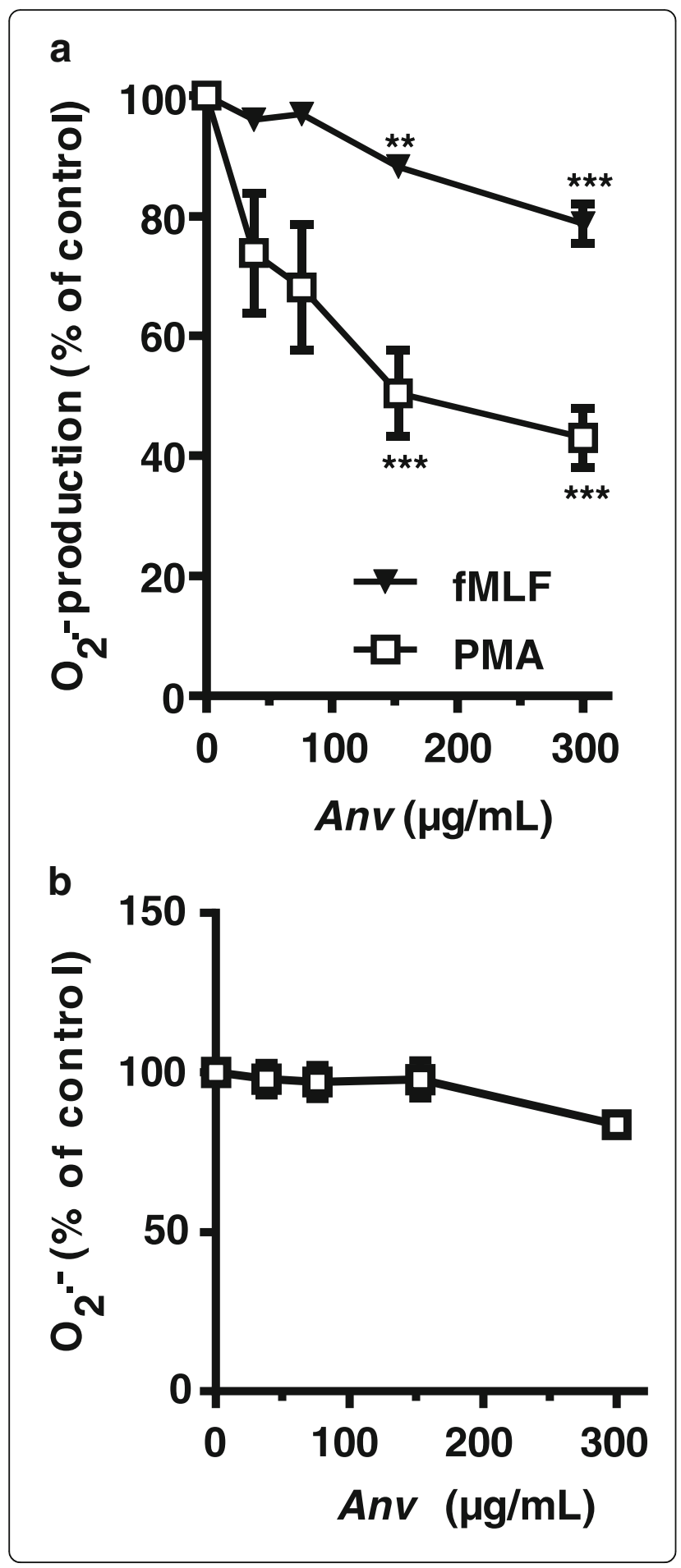

Fig. 1 Effect of Anv on superoxide anion production by human neutrophils. Human neutrophils were incubated at $37^{\circ} \mathrm{C}$ during $15 \mathrm{~min}$ in the presence or the absence of different concentrations of Anv (a). Then they were stimulated with either fMLF $\left(10^{-6} \mathrm{M}\right)$ or PMA (100 ng/mL) and simultaneously, superoxide production was measured using the cytochrome $c$ reduction assay at $550 \mathrm{~nm}$ in a spectrophotometer for $10 \mathrm{~min}$. The amount of superoxide produced is expressed as a percentage of values obtained when neutrophils were stimulated with $\mathrm{AMLF}$ or PMA alone. In $\mathbf{b}$, we investigated if Anv extract can scavenge superoxide anion. The $\mathrm{O}_{2}$ generation substrate xanthine and cytochrome $c$ were incubated with different concentrations of Anv extract at $30{ }^{\circ} \mathrm{C}$ during $15 \mathrm{~min}$. The enzyme xanthine oxidase was added and the amount $\mathrm{O}_{2}{ }^{-}$was measured by cytochrome $c$ reduction assay. All results are means \pm SEM of three or more separate experiments. ${ }^{* *} P<0.01,{ }^{* * *} P<0.0001$

inflammatory reactions $[1,8]$. Thus, inhibition of neutrophil hyper activation represents an interesting strategy to develop novel anti-inflammatory agents. There is increasing research in identifying novel natural plant products to integrate in conventional immunomodulators as they often have less side effects [11, 12]. Our data showed that water-soluble polysaccharides extract isolated from medicinal plants, $A n v$ inhibited fMLF- and PMA-induced superoxide anion $\left(\mathrm{O}_{2}{ }^{-}\right)$production in human neutrophils. Anv inhibited PMA-induced PKC activation resulting in the inhibition of PMA-induced phosphorylation and translocation of the NADPH oxidase subunit $\mathrm{p} 47^{\mathrm{phox}}$. Also, the $A n v$ extract inhibited MPO degranulation. These results suggest that polysaccharides isolated from Anv could exert a strong antiinflammatory effect by inhibiting neutrophil functions and by limiting reactive oxygen species (ROS) propagation to nearby tissues.

An important difference in the inhibitory effect of $A n v$ was observed on $\mathrm{O}_{2}{ }^{-}$produced in response to either fMLF and PMA. The pronounced effect on PMA versus fMLF may be due to different mechanisms including $\mathrm{O}_{2}{ }^{-}$scavenging since ROS-scavenging activity has been observed with some polysaccharide extracts $[25,26]$. Polysaccharide isolated from Artemisa tripartite has been shown to scavenge both $\mathrm{H}_{2} \mathrm{O}_{2}$ and $\mathrm{O}_{2}{ }^{-}$and their capacity to scavenge may be due to difference in polysaccharide composition and size [27]. The potent scavenging property of exogenous polysaccharides compounds represents a therapeutic potential for oxidative stressassociated inflammatory diseases. This has been recently highlighted in vivo by endogenous scavenging lectin such as Reg3 alpha which suppresses extracellular reactive oxygen species to protect from liver toxicity [28]. In our study, we found that $\mathrm{O}_{2}{ }^{-}$was not scavenged by Anv polysaccharide using an in vitro assay whereby superoxide anion $\left(\mathrm{O}_{2}{ }^{-}\right)$is produced by xanthine oxidase [27].

We thus explored how Anv could modulate neutrophil extracellular production of $\mathrm{O}_{2}^{--}$by $\mathrm{NADPH}$ oxidase 

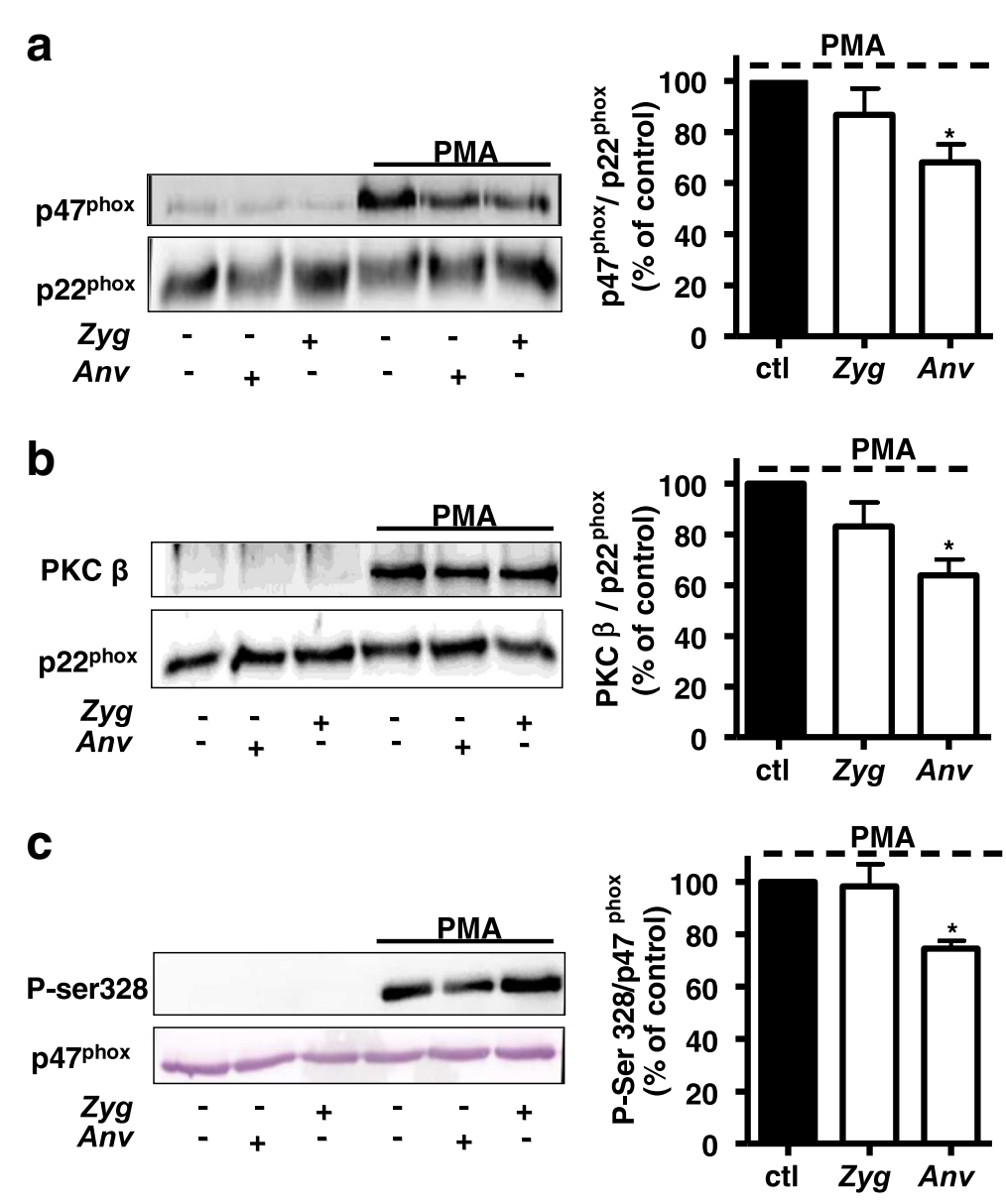

Fig. 2 Effect of Anv and Zyg on PKC and $p 47^{\text {phox }}$ translocation and on $p 47^{\text {phox }}$ phosphorylation in human neutrophils. In figures $\mathbf{a}$, $\mathbf{b}$ and $\mathbf{c}$, neutrophils were incubated for 15 mins at $37{ }^{\circ} \mathrm{C}$ either without or with $300 \mu \mathrm{g} / \mathrm{ml}$ of water-soluble extracts from Anv or Zygophyllum gaettulum (Zyg), followed by PMA stimulation for $8 \mathrm{~min}$. Zyg has no significant effect on phagocyte $\mathrm{O}_{2}-$ generation and represents a control versus Anv. Cells were lysed and membranes were purified as described in Methods and analyzed by SDS-PAGE and Western blot with anti-p47 ${ }^{\text {phox }}$ (a) or antiPKC $\beta$ (b) and anti-p22 $2^{\text {phox }} A b\left(p 22^{\text {phox }}\right)$ antibodies. Western blots from different experiments were scanned and the intensity of $p 47^{\text {phox }}$ and PKC $\beta$ translocation was expressed relative to the protein amount of $\mathrm{p} 22^{\text {phox }}$. The cumulated data is shown in the histogram as a percentage to control (PMA alone). In figure $\mathbf{c}$, immunoblotting was performed with anti-phospho-Ser328 Ab, or anti-p47 ${ }^{\text {phox }} \mathrm{Ab}$ (p47 ${ }^{\text {phox }}$ ). The cumulated data is shown in the histogram as a percentage to control (PMA alone). All the results are expressed as means \pm SEM of three or more separate experiments. * $P<0.05$, compared to control values

(NOX2) since several polysaccharide extracts have been shown to modulate phagocyte ROS production without or with scavenging activity $[29,30]$. Interestingly, it was shown that while water-insoluble chitosan derivatives can activate neutrophils by a phagocytosis mechanism, soluble ones would prime neutrophils and potentiate oxidative burst [29]. Thus, soluble polysaccharide extracts can have both stimulatory and inhibitory effects on neutrophil functions. In our study, it is unlikely that water-soluble polysaccharide extract of Anv directly inhibited the NOX2 enzyme since there was a preferential inhibition of $\mathrm{O}_{2}^{--}$production by NOX2 induced by two different stimulators, PMA or fMLF. Moreover, PMA represents not only a positive control but it is an appropriate tool to explore the signal transduction pathways involved in the activation of NOX2 and degranulation process of neutrophils [24, 31, 32]. PMA can directly activate the phospholipid-dependent protein kinase $\mathrm{C}$, which translocate to the plasma membrane and by phospohorylating NADPH oxidase components such as $\mathrm{p} 47^{\text {phox }}$ participates in the assembly and activation of NOX2 [33]. All PKC isoforms present in human neutrophils, including $P K C \beta$ are known to activate NADPH oxidase [24]. The biological relevance of PKC pathway was sustained by the use of opsonised zymosan, components of yeast cell wall, which activated a PKCdependent activation of NOX2 in neutrophils [34]. We found that $A n v$ inhibited the membrane translocation of $\mathrm{p} 47^{\mathrm{phox}}$ and PKC $\beta$ induced by PMA. Water-soluble polysaccharide extract of another North African medicinal 


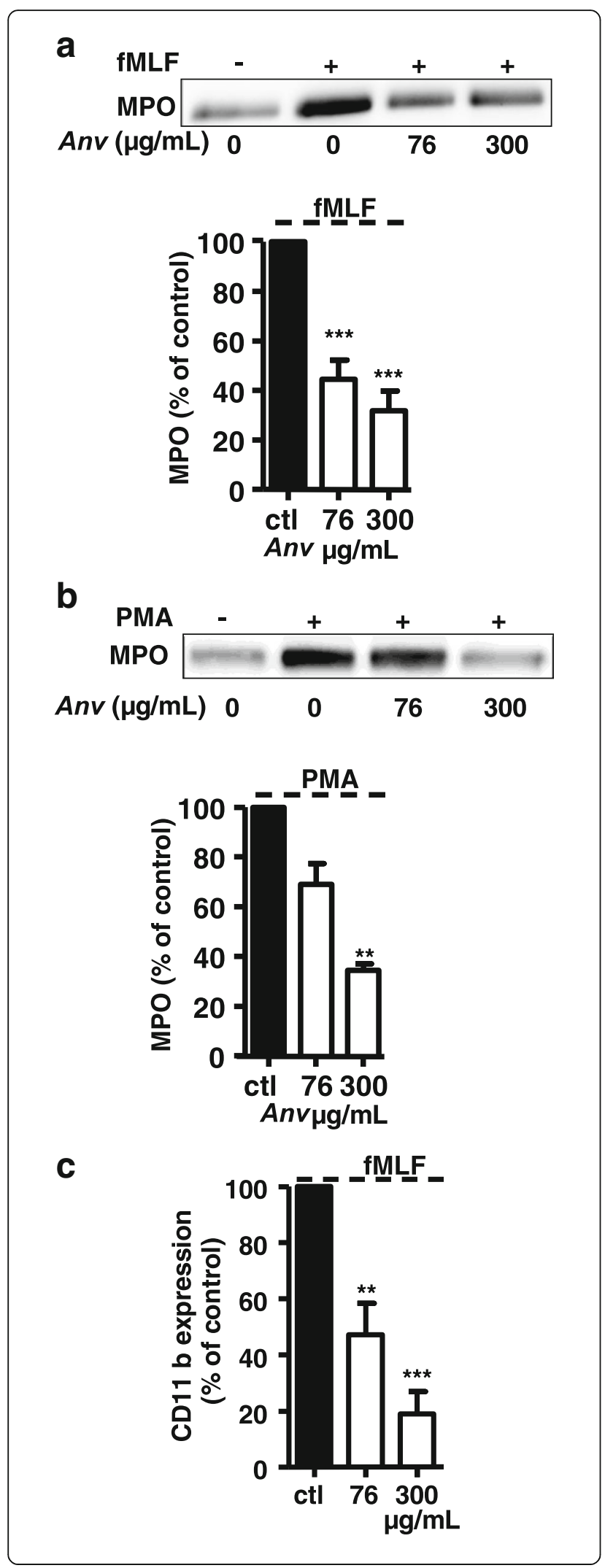

Fig. 3 Effect of Anv on fMLF- or PMA-induced degranulation by human neutrophils. Human neutrophils were incubated in the absence or the presence of different concentrations of Anv extract and then stimulated with either PMLF (a) for 5 min or PMA (b) for $15 \mathrm{~min}$. Cells were pelleted $\left(4^{\circ} \mathrm{C}\right)$ at $8000 \mathrm{~g}$ for $30 \mathrm{~s}$ and the extracell $\mu a r$ medium was centrifuged at 10,000 g during $12 \mathrm{~min}$ before analysis by SDS-PAGE and Western blot using anti-MPO antibody. The western blots from different experiments were scanned and the intensity of MPO was quantified by densitometry analysis. The histogram shows the percentage of MPO density as compared to control values with either fMLF or PMA only. In figure c, human neutrophils were similarly incubated as above either without or with Anv extract and then stimuated with fMLF for $5 \mathrm{~min}$. CD 11b expression at neutrophil surface was evaluated using a PE-conjugated anti-human CD11b monoclonal antibody and flow cytometric analysis as described in Methods. Histogram shows the percentage of CD11b expression relative to fMLF response. All results are expressed as means \pm SEM of three or more separate experiments. ${ }^{*} P<0.01$, *** $P<0.0001$, compared to control

plant $Z y g$, which is similarly used as Anv against inflammatory diseases, was also studied in order to explore their mechanisms. Further, $Z y g$ is sometimes given together with $A n v$ as traditional medicine. In contrast to $A n v$, we found that $Z y g$ barely inhibited $\mathrm{O}_{2}{ }^{-}$production by neutrophils in response to either PMA or fMLF (data not shown). In line with this observation, we found that $Z y g$ was ineffective in modulating the membrane translocation of $\mathrm{p} 47^{\text {phox }}$ and $\mathrm{PKC} \beta$ induced by PMA. The production of superoxide anions by NOX2 in human neutrophil is accompanied by extensive phosphorylation of $\mathrm{p} 47^{\text {phox }}$ which is an excellent substrate for PKC [24]. To further validate the action of $A n v$ on $\mathrm{PKC} / \mathrm{p} 47^{\text {phox }}$, we studied its effect on serine 328 of $\mathrm{p} 47^{\text {phox }}$, which is one of the most phosphorylated serine residues by PKC. The results obtained by using our raised antibody against this phosphorylated residue showed that $A n v$ polysaccharide was able to inhibit PMA-induced phosphorylation of serine 328 of $\mathrm{p} 47^{\text {phox }}$ as well as its translocation to neutrophil plasma membrane and $Z y g$ extract was ineffective. Altogether, the results indicate a clear effect of water-soluble $A n v$ polysaccharide extract on the modulation of PMA-induced superoxide anions.

The progression of inflammation is significantly affected by myeloperoxidase (MPO) released from azurophilic granules of neutrophils accumulated at inflammatory sites [35]. MPO-dependent oxidative system can damage host tissue through the generation of oxidants. There are some data suggesting that polysaccharides may influence the traffic of different granules in neutrophils and their degranulation in phagosomes or the extracellular environment. It has been recently shown that water soluble polysaccharides extracted from Bupleurum chinense inhibited fMLF-induced HL60 cell recruitment and involved the inhibition of rac-1 activation [36]. The traffic of 
cytosolic rac-1 or rac- 2 to plasma membrane is crucial in the assembly of functional NADPH oxidase and may represent a site of inhibitory action for polysaccharide extracts. Moreover, rac-2 serves has a selective role in the degranulation of neutrophils, a process which is independent of ROS production [37]. Further, the antiinflammatory aqueous extract of Punia granatum has been shown to selectively inhibit MPO activity of human neutrophils which depends on degranulation process [38]. In contrast, it has been shown that acidic polysaccharides isolated from the medicinal plant Tanacetum vulgare $\mathrm{L}$. can enhance neutrophil MPO release [39]. Thus, it is important to test the effect of $A n v$ on neutrophil degranulation initiated by fMLF or PMA. The effect on azurophilic or specific granules was estimated by following MPO and CD11b expression respectively. We could show that $A n v$ extract was more effective in inhibiting fMLF- than PMAinduced MPO release in the extracellular medium. Also, the surface expression of $\mathrm{CD} 11 \mathrm{~b}$, a sensitive marker of PMN activation by fMLF was inhibited by Anv. Our results indicate that $A n v$ polysaccharide can inhibit both PMA and FMLF induced degranulation processes which involve a large group of intracellular signalling molecules [40].

\section{Conclusion}

We demonstrated that $A n v$ polysaccharides have a strong antioxidant action on neutrophils as summarized in Fig. 4. Moreover, $A n v$ was very efficient at limiting

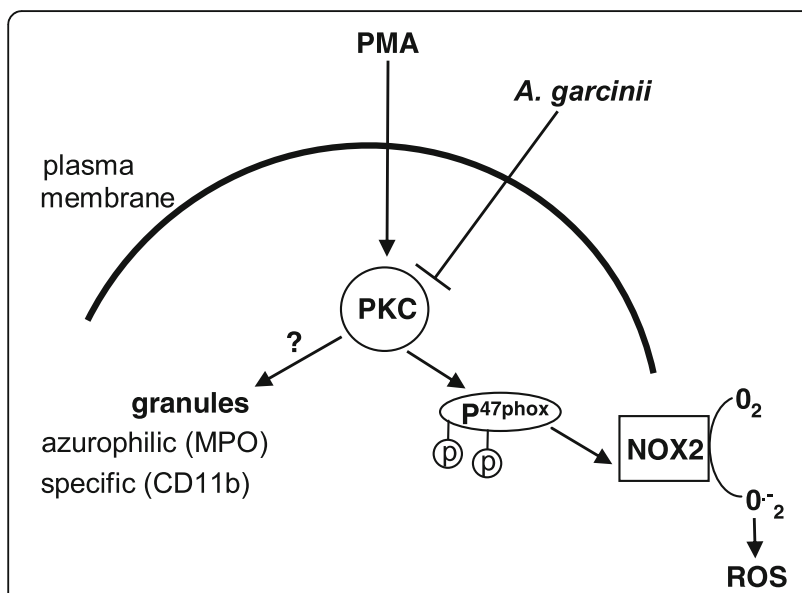

Fig. 4 Mechanism of action of A. garcininii (Anv). Polysaccharides extract from Anv strongly inhibits neutrophils response induced by phorbol myristate acetate (PMA) an activator of Protein Kinase $C$ (PKC). Activation of PKC leads to specific phosporylation of $p 47^{\text {phox }}$ and its translocation to plasma membrane to activate NADPH oxidase (NOX2) which produces ROS. Anv prevents this activation by inhibiting PKC and thus preventing p47 ${ }^{\text {phox }}$ phosphorylation and its translocation. Further, Anv by its inhibitory action on PKC, is also able to counteract the degranulation of azurophilic and specific granules of activated neutrophils
NADPH oxidase activation by inhibiting the phosphorylation of $\mathrm{p} 47^{\text {phox }}$ and its translocation to the plasma membrane. In addition, the extract inhibited MPO degranulation. In conclusion, by inhibiting both extracellular ROS production and neutrophil's degranulation, Anv has strong anti-inflammatory properties which make it a promising candidate for further medicinal applications.

\section{Additional file}

Additional file 1: Dose-effect of Anvillea garcinii (Anv), Zygophyllum gaetulum (Zyg) and aspirin (Asp) on human neutrophils ROS production. Human neutrophils were incubated with increasing concentration of Anv $(38-300 \mu \mathrm{g} / \mathrm{mL})$, Zyg $(38-300 \mu \mathrm{g} / \mathrm{mL})$ or Asp $(62-500 \mu \mathrm{g} / \mathrm{mL}) 15 \mathrm{~min}$ before stimulation with A) fMLF $\left(10^{-6} \mathrm{M}\right)$ or B) PMA (100ng/ $\left.\mathrm{mL}\right)$. ROS was measured by luminol-amplified chemiluminescence and data are expressed as percentage to control (fLMF or PMA alone). All results are means \pm SEM of three or more separate experiments. (DOC $35 \mathrm{~kb}$ )

\section{Abbreviations}

Anv: Anvillea garcinii Coss. \& Durieu; fMLF: N-formyl-methionyl-leucylphenylalanine; MPO: Myeloperoxidase; NOX2: Phagocyte NADPH oxidase; PMA: Phorbol myristate acetate; Zyg: Zygophyllum gaetulum

\section{Acknowledgements}

We thank Dr. Tarek Bousetta and Dr. Stuart Moore from INSERM U1149, Paris France for their excellent scientific comments.

\section{Funding}

There were no grants.

\section{Availability of data and materials}

Specimens of the two tested plants were deposited at the herbarium of the university with the voucher specimen; (No.A.g.2010-1) for Anvillea garcinii Coss. \& Durieu and voucher; (No.A.g.2010-2) for Zygophyllum gaetulum. Materials and data of our study are available to other researches upon request.

\section{Authors' contributions}

$\mathrm{HB}$ and DB collected the plants and prepared the extracts. $\mathrm{HB}$ and $\mathrm{MH}-\mathrm{N}$ and $\mathrm{VM}$ conducted the experiments and the analysis and interpretation of data. J El-B, J-C M and DB conceived the research idea and prepared the final manuscript. All authors read and approved the paper before submission.

\section{Competing interests}

The authors declare that they have no competing interests.

\section{Consent for publication}

This information is not applicable.

Ethics approval and consent to participate

Blood was from healthy subjects who volunteered and came from the blood bank (EFS, Paris, France). This study was approved by our institutional Human Ethics Committee with reference number 2015012778 and there were written informed consents.

\section{Author details}

1INSERM, U1149, CNRS-ERL8252, Centre de Recherche sur I'Inflammation (CRI), 16 rue Henri Huchard, 75018 Paris, France. ${ }^{2}$ Université Paris Diderot, Sorbonne, 75018 Paris, France. ${ }^{3}$ Laboratoire d'Excellence Inflamex, Faculté de Médecine, Site Xavier Bichat, 75018 Paris, France. ${ }^{4}$ AP-HP, HUPNVS Bichat-Claude Bernard, UF Dysfonctionnements Immunitaires, 75018 Paris, France. ${ }^{5}$ Laboratoire de Biologie, eau et Environnement - Département de Biologie, Faculté SNV/ STU, Université 8 mai 1945 - Guelma, BP 401, Guelma 24000, Algeria 
Received: 3 May 2016 Accepted: 20 October 2016 Published online: 03 November 2016

\section{References}

1. El-Benna J, Hurtado-Nedelec M, Marzaioli V, Marie J-C, Gougerot-Pocidalo M-A, Dang PM-C. Priming of the neutrophil respiratory burst: role in host defense and inflammation. Immunol Rev. 2016:273:180-93. [cited 2016 Sep 9]. Available from: http://www.ncbi.nlm.nih.gov/pubmed/27558335

2. Lemanske RF, Busse WW. Asthma. JAMA. 1997;278:1855-73. [cited 2016 Jan 13]. Available from: http://www.ncbi.nlm.nih.gov/pubmed/9396647.

3. El-Benna J, Dang PM-C, Gougerot-Pocidalo MA, Marie JC, Braut-Boucher F. p47phox, the phagocyte NADPH oxidase/NOX2 organizer: structure, phosphorylation and implication in diseases. Exp Mol Med. 2009:41:217-25. [cited 2015 Oct 11]. Available from: http://www.pubmedcentral.nih.gov/ articlerender.fcgi?artid=2679237\&tool=pmcentrez\&rendertype=abstract.

4. Vignais PV. The superoxide-generating NADPH oxidase: structural aspects and activation mechanism. Cell Mol Life Sci. 2002;59:1428-59. [cited 2015 Dec 4] Available from: http://www.ncbi.nlm.nih.gov/pubmed/12440767.

5. El-Benna J, Hayem G, Dang PM-C, Fay M, Chollet-Martin S, Elbim C, et al. NADPH oxidase priming and p47phox phosphorylation in neutrophils from synovial fluid of patients with rheumatoid arthritis and spondylarthropathy. Inflammation. 2002;26:273-8. [cited 2015 Dec 4]. Available from: http:// www.ncbi.nlm.nih.gov/pubmed/12546136.

6. Chedid P, Hurtado-Nedelec M, Marion-Gaber B, Bournier O, Hayem G, Gougerot-Pocidalo M-A, et al. Adiponectin and its globular fragment differentially modulate the oxidative burst of primary human phagocytes. Am J Pathol. 2012;180:682-92. [cited 2015 Dec 4]. Available from: http:// www.ncbi.n/m.nih.gov/pubmed/22119038.

7. Lacy P. Mechanisms of degranulation in neutrophils. Allergy Asthma Clin Immunol. 2006;2:98-108. [cited 2016 Jan 13]. Available from: http:// www.pubmedcentral.nih.gov/articlerender.fcgi?artid=2876182\&tool= pmcentrez\&rendertype $=$ abstract

8. Haick AK, Rzepka JP, Brandon E, Balemba OB, Miura TA. Neutrophils are needed for an effective immune response against pulmonary rat coronavirus infection, but also contribute to pathology. J Gen Virol. 2014;95:578-90. [cited 2016 Sep 9]. Available from: http://www.ncbi.nlm. nih.gov/pubmed/24323639.

9. Stark TD, Germann D, Balemba OB, Wakamatsu J, Hofmann T. New highly in vitro antioxidative 3,8"-linked Biflav(an)ones and Flavanone-C-glycosides from Garcinia buchananii stem bark. J Agric Food Chem. 2013;61:12572-81. [cited 2016 Sep 9]. Available from: http://www.ncbi.n/m.nih.gov/pubmed/ 24295222.

10. Mawa S, Jantan I, Husain K. Isolation of terpenoids from the stem of Ficus aurantiaca Griff and their effects on reactive oxygen species production and chemotactic activity of neutrophils. Molecules. 2016;21:9. [cited 2016 Sep 9]. Available from: http://www.ncbi.nlm.nih.gov/pubmed/26742027.

11. Stark TD, Mtui DJ, Balemba OB. Ethnopharmacological survey of plants used in the traditional treatment of gastrointestinal pain, inflammation and diarrhea in Africa: future perspectives for integration into modern medicine. Animals. 2013;3:158-227. [cited 2016 Sep 9]. Available from: http://www. ncbi.nlm.nih.gov/pubmed/26487315.

12. Schepetkin IA, Quinn MT. Botanical polysaccharides: macrophage immunomodulation and therapeutic potential. Int Immunopharmacol. 2006 6:317-33. [cited 2016 Jan 13]. Available from: http://www.ncbi.nlm.nih.gov/ pubmed/16428067.

13. Rimbau V, Cerdan C, Vila R, Iglesias J. Antiinflammatory activity of some extracts from plants used in the traditional medicine of north-African countries (II). Phytother Res. 1999;13:128-32. [cited 2016 Jan 13]. Available from: http://www.ncbi.n/m.nih.gov/pubmed/10190185.

14. Bellakhdar J, Claisse R, Fleurentin J, Younos C. Repertory of standard herbal drugs in the Moroccan pharmacopoea. J Ethnopharmacol. 1991;35:123-43. [cited 2016 Jan 13]. Available from: http://www.ncbi.nlm.nih.gov/pubmed/ 1809818.

15. Hammiche V, Maiza K. Traditional medicine in Central Sahara: pharmacopoeia of Tassili N'ajjer. J Ethnopharmacol. 2006;105:358-67. [cited 2016 Jan 13]. Available from: http://www.ncbi.nlm.nih.gov/pubmed/16414225.

16. Jamila F, Mostafa E. Ethnobotanical survey of medicinal plants used by people in Oriental Morocco to manage various ailments. J Ethnopharmacol. 2014;154:76-87. [cited 2016 Jan 13]. Available from: http://www.ncbi.nlm. nih.gov/pubmed/24685583.
17. Boussetta T, Gougerot-Pocidalo M-A, Hayem G, Ciappelloni S, Raad H, Arabi Derkawi $\mathrm{R}$, et al. The prolyl isomerase Pin1 acts as a novel molecular switch for TNF-alpha-induced priming of the NADPH oxidase in human neutrophils. Blood. 2010;116:5795-802. [cited 2015 Dec 14]. Available from: http://www.pubmedcentral.nih.gov/articlerender. fcgi?artid=3031377\&tool=pmcentrez\&rendertype=abstract.

18. Bendjeddou D, Lalaoui K, Satta D. Immunostimulating activity of the hot water-soluble polysaccharide extracts of Anacyclus pyrethrum, Alpinia galanga and Citrullus colocynthis. J Ethnopharmacol. 2003;88: 155-60. [cited 2016 Jan 13]. Available from: http://www.ncbi.nlm.nih. gov/pubmed/12963136.

19. Bradford MM. A rapid and sensitive method for the quantitation of microgram quantities of protein utilizing the principle of protein-dye binding. Anal Biochem. 1976;72:248-54. [cited 2014 Jul 9]. Available from: http://www.ncbi.n/m.nih.gov/pubmed/942051.

20. Dubois M, Gilles K, Hamilton JK, Rebers PA, Smith F. A colorimetric method for the determination of sugars. Nature. 1951;168:167. [cited 2015 Nov 28]. Available from: http://www.ncbi.nlm.nih.gov/pubmed/14875032.

21. Ait El Cadi M, Makram S, Ansar M, Khabbal Y, Alaoui K, Faouzi MA, et al. Anti-inflammatory activity of aqueous and ethanolic extracts of Zygophyllum gaetulum. Ann Pharm Fr. 2012;70:113-6. [cited 2016 Jan 13]. Available from: http://www.ncbi.nlm.nih.gov/pubmed/22500963.

22. El-Benna J, Ruedi JM, Babior BM. Cytosolic guanine nucleotide-binding protein Rac2 operates in vivo as a component of the neutrophil respiratory burst oxidase. Transfer of Rac2 and the cytosolic oxidase components p47phox and p67phox to the submembranous actin cytoskeleton during oxidase. J Biol Chem. 1994;269:6729-34. [cited 2015 Dec 4]. Available from: http://www.ncbi.nlm.nih.gov/pubmed/8120032.

23. Laemmli UK. Cleavage of structural proteins during the assembly of the head of bacteriophage T4. Nature. 1970;227:680-5. [cited 2014 Jul 9]. Available from: http://www.ncbi.nlm.nih.gov/pubmed/5432063.

24. Fontayne A, Dang PM-C, Gougerot-Pocidalo M-A, El-Benna J. Phosphorylation of p47phox sites by PKC alpha, beta II, delta, and zeta: effect on binding to p22phox and on NADPH oxidase activation. Biochemistry. 2002:41:7743-50. [cited 2016 Jan 13]. Available from: http://www.ncbi.nlm.nih.gov/pubmed/ 12056906.

25. Huang X, Li Q, Li H, Guo L. Neuroprotective and antioxidative effect of cactus polysaccharides in vivo and in vitro. Cell Mol Neurobiol. 2009:29: 1211-21. [cited 2016 Jan 13]. Available from: http://www.ncbi.nlm.nih.gov/ pubmed/19517228.

26. Sakagami H, Kohno S, Takeda M, Nakamura K, Nomoto K, Ueno I, et al. O2scavenging activity of lignins, tannins and PSK. Anticancer Res. 1992;12: 1995-2000. [cited 2016 Jan 13]. Available from: http://www.ncbi.nlm.nih. gov/pubmed/1338273

27. Xie G, Schepetkin IA, Siemsen DW, Kirpotina LN, Wiley JA, Quinn MT. Fractionation and characterization of biologically-active polysaccharides from Artemisia tripartita. Phytochemistry. 2008:69:1359-71. [cited 2016 Jan 13]. Available from: http://www.pubmedcentral.nih.gov/articlerender.fcgi?artid= 2440954\&tool=pmcentrez\&rendertype=abstract.

28. Moniaux N, Darnaud M, Garbin K, Dos Santos A, Guettier C, Samuel D, et al. The Reg3a (HIP/PAP) lectin suppresses extracellular oxidative stress in a murine model of acute liver failure. PLoS One. 2015;10:e0125584. [cited 2016 Jan 13]. Available from: http://www.pubmedcentral.nih.gov/ articlerender.fcgi?artid=4418718\&tool=pmcentrez\&rendertype=abstract.

29. Morimoto M, Saimoto H, Usui H, Okamoto Y, Minami S, Shigemasa Y. Biological activities of carbohydrate-branched chitosan derivatives. Biomacromolecules. 2001;2:1133-6. [cited 2016 Jan 13]. Available from: http://www.ncbi.n/m.nih.gov/pubmed/11777384.

30. Nikolova M, Ambrozova G, Kratchanova M, Denev P, Kussovski V, Ciz M, et al. Effects of pectic polysaccharides isolated from leek on the production of reactive oxygen and nitrogen species by phagocytes. J Med Food. 2013;16: 711-8. [cited 2016 Jan 13]. Available from: http://www.pubmedcentral.nih.gov/ articlerender.fcgi?artid=3751262\&tool=pmcentrez\&rendertype=abstract.

31. Heyworth PG, Badwey JA. Continuous phosphorylation of both the 47 and the $49 \mathrm{kDa}$ proteins occurs during superoxide production by neutrophils. Biochim Biophys Acta. 1990;1052:299-305. [cited 2016 Jan 13]. Available from: http://www.ncbi.nlm.nih.gov/pubmed/2159348.

32. Karlsson A, Dahlgren C. Assembly and activation of the neutrophil NADPH oxidase in granule membranes. Antioxid Redox Signal. 2002;4:49-60. [cited 2016 Jan 13]. Available from: http://www.ncbi.nlm.nih.gov/ pubmed/11970843. 
33. Raad H, Paclet M-H, Boussetta T, Kroviarski Y, Morel F, Quinn MT, et al. Regulation of the phagocyte NADPH oxidase activity: phosphorylation of gp91 phox/NOX2 by protein kinase $C$ enhances its diaphorase activity and binding to Rac2, p67phox, and p47phox. FASEB J. 2008;23:1011-22. [cited 2016 Jan 11]. Available from: http://www.pubmedcentral.nih.gov/ articlerender.fcgi?artid=2660639\&tool=pmcentrez\&rendertype=abstract.

34. Sergeant S, MCPhail LC. Opsonized zymosan stimulates the redistribution of protein kinase C isoforms in human neutrophils. J Immunol. 1997;159:2877-85. [cited 2016 Jan 13]. Available from: http://www.ncbi.nlm.nih.gov/pubmed/ 9300711.

35. Lazarević-Pasti T, Leskovac A, Vasić V. Myeloperoxidase Inhibitors as Potential Drugs. Curr Drug Metab. 2015;16:168-90. [cited 2016 Jan 13]. Available from: http://www.ncbi.n/m.nih.gov/pubmed/26279325.

36. Tong H, Tian D, He Z, Liu Y, Chu X, Sun X. Polysaccharides from Bupleurum chinense impact the recruitment and migration of neutrophils by blocking fMLP chemoattractant receptor-mediated functions. Carbohydr Polym. 2013; 92:1071-7. [cited 2016 Jan 13]. Available from: http://www.ncbi.nIm.nih.gov/ pubmed/23399130.

37. Abdel-Latif D, Steward M, Macdonald DL, Francis GA, Dinauer MC, Lacy P. Rac2 is critical for neutrophil primary granule exocytosis. Blood. 2004;104:832-9. [cited 2015 Dec 22]. Available from: http://www.ncbi.nlm.nih.gov/pubmed/ 15073033

38. Bachoual R, Talmoudi W, Boussetta T, Braut F, El-Benna J. An aqueous pomegranate peel extract inhibits neutrophil myeloperoxidase in vitro and attenuates lung inflammation in mice. Food Chem Toxicol. 2011;49:1224. [cited 2016 Jan 13]. Available from: http://www.ncbi.nlm.nih.gov/pubmed/ 21376769.

39. Xie G, Schepetkin IA, Quinn MT. Immunomodulatory activity of acidic polysaccharides isolated from Tanacetum vulgare L. Int Immunopharmacol. 2007;7:1639-50. [cited 2016 Sep 9]. Available from: http://www.ncbi.nlm.nih. gov/pubmed/17996673.

40. El-Benna J, Dang PM-C, Gougerot-Pocidalo M-A, Elbim C. Phagocyte NADPH oxidase: a multicomponent enzyme essential for host defenses. Arch Immunol Ther Exp (Warsz). 2005;53:199-206. [cited 2015 Aug 24]. Available from: http://www.ncbi.nlm.nih.gov/pubmed/15995580.

\section{Submit your next manuscript to BioMed Central and we will help you at every step:}

- We accept pre-submission inquiries

- Our selector tool helps you to find the most relevant journal

- We provide round the clock customer support

- Convenient online submission

- Thorough peer review

- Inclusion in PubMed and all major indexing services

- Maximum visibility for your research

Submit your manuscript at www.biomedcentral.com/submit

) Biomed Central 